\title{
Antioxidant and Anti-Inflammatory Effects of Peanut Skin Extracts
}

\author{
Wanida E. Lewis ${ }^{1}$, Gabriel K. Harris ${ }^{1}$, Timothy H. Sanders ${ }^{2}$, Brittany L. White ${ }^{2}$, Lisa L. Dean ${ }^{2 *}$ \\ ${ }^{1}$ Department of Food, Bioprocessing, and Nutrition Sciences, North Carolina State University, Raleigh, USA; ${ }^{2}$ Market Quality and \\ Handling Research Unit, Agricultural Research Service, United States Department of Agriculture, Raleigh, USA. \\ Email: *Lisa.Dean@ars.usda.gov
}

Received April 12 $2^{\text {th }}, 2013$; revised May 12 $2^{\text {th }}, 2013$; accepted May 19 ${ }^{\text {th }}, 2013$

Copyright (C) 2013 Wanida E. Lewis et al. This is an open access article distributed under the Creative Commons Attribution License, which permits unrestricted use, distribution, and reproduction in any medium, provided the original work is properly cited.

\begin{abstract}
Peanut skins are regarded as a low economic value by-product of the peanut industry; however, they contain high levels of bioactive compounds including catechins and procyanidins, which are known for their health-promoting properties. The in vitro antioxidant activity of peanut skin extracts (PSE) has been reported but the associated anti-inflammatory properties have not been widely examined. This study investigated the anti-inflammatory effects of PSE on the pro-inflammatory enzyme, Cyclooxygenase-2 (COX-2) protein expression, on its downstream product, prostaglandin $\mathrm{E}_{2}$ $\left(\mathrm{PGE}_{2}\right)$, and on nitrous oxide (NO) levels. Defatted peanut skins were extracted using two aqueous solvent mixtures (50\% acetone and $90 \%$ ethanol), in order to compare the effects of the two solvent systems on antioxidant and anti-inflammatory properties. PSE antioxidant activity was determined by the hydrophilic oxygen radical absorbance capacity (H-ORAC) assay, while total phenolics were determined by the Folin-Ciocalteu assay and flavan-3-ols and procyanidins were quantified by HPLC. Acetone extracted PSE (A-PSE) exhibited numerically, but not statistically higher H-ORAC and total phenolic values than the ethanol extracted PSE (E-PSE) (1836 $\mu \mathrm{mol}$ Trolox/100 g and 67.9 $\mathrm{mg} \mathrm{GAE} / \mathrm{g}$, and $1830 \mu \mathrm{mol}$ Trolox/100 g and $51.8 \mathrm{GAE} / \mathrm{g}$ respectively). A-PSE also had higher levels of flavan-3-ols and procyanidins than E-PSE. RAW 264.7 cells were pretreated with $1.0 \%, 2.5 \%$ and $5.0 \%(\mathrm{v} / \mathrm{v})$ of A-PSE or E-PSE and induced with the inflammatory marker, lipopolysaccharide (LPS) for 12 hours. COX-2 protein expression, measured by Western blotting was significantly $(\mathrm{p}<0.05)$ inhibited by A-PSE and E-PSE at $2.5 \%$ and $5.0 \%$ concentrations. $\mathrm{PGE}_{2}$ and NO levels measured by ELISA, were significantly $(\mathrm{p}<0.05)$ decreased with increasing added levels of A-PSE and E-PSE suggesting that A-PSE and E-PSE not also possess similar antioxidant properties, but also exhibit similar anti-inflammatory effects.
\end{abstract}

Keywords: Peanut Skins; Antioxidants; Anti-Inflammatory; Cyclooxygenase (COX-2); Prostaglandin $\mathrm{E}_{2}\left(\mathrm{PGE}_{2}\right)$; Nitric Oxide (NO); Procyanidins

\section{Introduction}

Peanuts (Arachis hypogaea L.) are one of the most widely used legumes in the world. Several phytochemicals including resveratrol, flavan-3-ols and proanthocyanidins have been identified in peanuts and evaluated for their potential health benefits [1-4]. Research has shown that peanut consumption provides such health benefits due to high levels of certain phytochemicals [5]. These same phytochemicals are also found in fruits, such as grapes, and have been valued for their health promoting abilities including anti-cancer and anti-inflammatory activities [6]. By-products of the peanut industry which include peanut

\footnotetext{
"Corresponding author.
}

plant leaves, roots, hulls, shells and skins have also been identified as rich sources of phytochemicals, suggesting that the bioactivity found in fruits and vegetables could possibly be present, although currently these plant parts have little economic value [5]. Of these materials, peanut skins are most commonly used as low cost fillers in animal feed but are known to have an astringent taste and anti-nutrient properties [7]. The antioxidant activity of peanut skins has been reported [8-11], but there are no reports in the scientific literature regarding the relationship between antioxidants, their activity, and anti-inflammatory properties of peanut skins.

Prostaglandins (PG) are important intermediates in inflammation and inflammatory associated cancers. These 
compounds are messengers that contain the 20-carbon polyunsaturated fatty acid, aracadonic acid [12]. They are found in many tissue types and serve as autocrine or paracrine lipid mediators acting on mast cells, platelets, and other surface cells [13]. In humans, PG act on a range of cells resulting in effects on blood clotting, ovulation, initiation of labor, wound healing, immune response, nerve growth and development [14]. The key regulatory enzyme of PG biosynthesis, in particular $\mathrm{PGE}_{2}$, is cyclooxygenase $(\mathrm{COX})$. Cyclooxygenase is a bifunctional enzyme that is required for the production of $\mathrm{PG}$ [15].

Two isoforms, COX-1 and COX-2 have been identified $[13,15]$. Although COX-1 and COX-2 are structurally homologous having similar kinetic properties, they are expressed in different parts of the body [15]. Most cell types express COX-1 at constant levels. The PG products of COX-1 help to mediate homeostasis and restorative functions like gastric epithelial cytoprotection and homeostasis. COX-2 is expressed in the central nervous system (CNS) but generally not in cells. However, when COX-2 is expressed, the protein levels reach their peak then quickly fade within a matter of hours after a single stimulus [12]. Importantly, inflammation refers to a group of stimuli known to induce COX-2. These stimuli include bacterial lipopolysaccharide (LPS), tumor necrosis factor (TNF- $\alpha$ ), and the cytokines, interleukin-1 (IL-1) and interleukin-2 (IL-2) [15]. This suggests that COX-2 generates PG that regulate an inflammatory response. The anti-inflammatory cytokines such as IL-4, IL-10 and IL-13 have been shown to decrease the induction of COX-2 [15].

$\mathrm{PGE}_{2}$ is the major PG synthesized by macrophages. COX-2 expression occurs in response to integral factors such as cytokines, or added factors such as LPS, resulting in the production of $\mathrm{PGE}_{2}$ [16]. Several studies have shown formation of $\mathrm{PGE}_{2}$ can be enhanced or inhibited by certain phenolic compounds in foods, and as a result, affect the inflammatory response [17-19]. Therefore, it is useful to investigate how foods can affect COX-2 expression and PG formation in terms of pathophysiological conditions associated with inflammation. In addition, activated macrophages have the ability to express inducible nitric oxide synthase (iNOS) which in turn, catalyzes L-arginine to produce nitric oxide (NO), thus making it responsible for the prolonged production of $\mathrm{NO}[20,21]$. High outputs of NO by iNOS are also thought to induce inflammation.

This study was designed to determine the antioxidant activity and anti-inflammatory properties of peanut skin extracts (PSE). PSE was prepared by extraction using aqueous solvent mixtures ( $50 \%$ acetone or $90 \%$ ethanol) and then freeze drying. The antioxidant activity was investigated using the hydrophilic oxygen radical absorbance capacity (H-ORAC) and the total phenol content (TPC) was determined using the Folin-Ciocalteu assay. The concentration of flavan-3-ols and procyanidins were also determined by High Performance Liquid Chromatography (HPLC). The anti-inflammatory effects of PSE in RAW 264.7 cells were evaluated upon induction with an inflammatory marker, in this case lipopolysacharride (LPS). The anti-inflammatory effect of PSE against $\mathrm{PGE}_{2}$ and COX-2 expression by the cells was accessed using Western blotting and ELISA. The production of NO was monitored using the Greiss Assay.

\section{Materials and Methods}

\subsection{Chemicals and Sample Collection}

Peanut skins were supplied by a commercial peanut processor (Jimbo's Jumbos, Edenton, NC). RAW 264.7 cells, a murine monocyte/macrophage cell line, were obtained from American Type Culture Collection (Manassas, VA). Dulbecco's modified Eagle's medium (DMEM), Fetal Bovine Serum (FBS) and antibiotics (100x Penicillin Streptomycin Glutamine) were purchased from Invitrogen (Carlsbad, CA). Lipopolysaccharide (LPS) from Escherichia coli Serotype 0111:B4 was purchased from Sigma Aldrich (St. Louis, MO). $\beta$-actin from rabbit monoclonal antibody (mAB) was obtained from Cell Signaling (Danvers, MA) and COX-2 polycolonal antibody was purchased from Caymen Chemical Corp (Ann Arbor, MI). All other chemicals and solvents were purchased from the Thermo Fisher Corporation (Fairlawn, NJ) unless otherwise noted.

\subsection{Preparation of Peanut Skin Extracts}

Peanut skins were defatted by overnight mechanical stirring in an excess of hexane at room temperature with protection from light. Hexane containing the dissolved lipid fraction was decanted and the skins were resuspended in fresh hexane and stirred for an additional $3 \mathrm{hr}$. After removal of the hexane, the now defatted skins were allowed to air dry overnight, and then milled to a fine powder using a Model 4 Wiley Mill (Arthur H. Thomas Co., Philadelphia, PA). A $10 \mathrm{~g}$ portion of the milled, defatted skins was extracted with $100 \mathrm{~mL}$ of solvent mixture (acetone/water, 50/50 (v/v) or ethanol/water, 90/10 $(\mathrm{v} / \mathrm{v}))$ at room temperature by stirring for $120 \mathrm{~min}$. After extraction, the slurry was vacuum filtered through Whatman No. 1 paper (GE Healthcare Life Sciences, Piscataway, NJ) and the supernatant was collected. The insoluble material on the filter was washed with 2 portions of $25 \mathrm{~mL}$ of the original extraction solvent (acetone/water or ethanol/water) and the washings added to the supernatant. The solvent (ethanol or acetone) was removed from the extraction solvent at $50^{\circ} \mathrm{C}$ using a vacuum rotary evaporator (Büchi Labortechnik AG, Flawil, Switzerland). After all the solvent was removed, the crude extracts in the remaining water were freeze-dried using a VirTis 
Freeze Dryer (VirTis, Gardiner, NY). The resulting powders were stored at $-20^{\circ} \mathrm{C}$ protected from light until analyzed. The extraction was repeated in triplicate for each solvent system.

\subsection{HPLC Analysis of Procyanidins}

Monomeric flavan-3-ols and procyanidins present in peanut skin extracts (PSE) were separated according to degree of polymerization by HPLC analysis as previously described [22]. Briefly, extracts $(10 \mathrm{~mL})$ were evaporated to dryness using a SpeedVac concentrator (ThermoSavant, Holbrook, NY) and resuspended in $2 \mathrm{~mL}$ acetone/ water/acetic acid (70/29.5/0.5 v/v/v) and filtered through a $0.45 \mu \mathrm{m}$ PVDF filter prior to injection on the HPLC (Dionex Summit System, Dionex Corp., Sunnyvale, CA). Compounds were separated on a $5 \mu \mathrm{m}, 250 \times 4.6 \mathrm{~mm}$ Luna silica column (Phenomenex, Torrance, CA) and peaks were detected by fluorescence (excitation at 276 $\mathrm{nm}$, emission at $316 \mathrm{~nm}$ ). Peaks were quantified based on external calibration curves of commercial standards. Oligomers with DP $>4$ and polymers were quantified as tetramer equivalents. Results were expressed as mg procyandin per gram of peanut skins.

\subsection{Analysis of Total Phenolic Content (TPC)}

The TPC of the PSE was determined using the Folin-Ciocalteau colorimetric method [23]. Briefly, $0.1 \mathrm{~g}$ of the dried extract was dissolved into $1 \mathrm{~mL}$ of water. $100 \mu \mathrm{L}$ of this solution was mixed with $0.5 \mathrm{~mL}$ of Folin-Ciocalteau reagent (Sigma Chemical Corp., St. Louis, MO). $1.5 \mathrm{~mL}$ of a sodium bicarbonate solution $(60 \mathrm{~g} / \mathrm{L})$ was then immediately added to the extract solution. The mixture was then incubated for $120 \mathrm{~min}$ at $22^{\circ} \mathrm{C}$ in a water bath. The absorbance of the solution was read at $725 \mathrm{~nm}$ using a Shimadzu Pharma UV-1700 Spectrophotometer (Columbia, MD). The TPC was calculated by comparison with a standard curve prepared using gallic acid. The results were expressed as mg of gallic acid equivalents (GAE) per gram of peanut skins.

\subsection{Antioxidant Activity}

The protocol of Prior et al. [24] was used to measure Hydrophilic Oxygen Radical Absorbance Capacity activity (H-ORAC). For the standard curve, solutions of Trolox (Aldrich Chemicals, Milwaukee, WI) were prepared in $75 \mathrm{mM}$ phosphate buffer, $\mathrm{pH} 7.4$ at concentrations over a range of 3.12, to $50 \mu \mathrm{M}$. The PSE were diluted in $75 \mathrm{mM}$ phosphate buffer in a ratio of 1:10,000. Fluorescein (Reidel-deHaen, Seelze, Germany) (70 nM in $75 \mathrm{mM}$ phosphate buffer) was used as the fluorophore in the reaction and $153 \mathrm{mM}$ 2,2'-azobis(2-amidinopropane) dihydrochloride (AAPH) (Wako Chemicals, Richmond, VA) was used as the peroxyl radical generator. Diluted samples or standards $(130 \mu \mathrm{L})$ were added to the wells of a flatbottom black 96 well microplate (Corning, Acton, MA). Blanks were prepared by adding $130 \mu \mathrm{L}$ of buffer only to plate wells. Fluorescein $(60 \mu \mathrm{L})$ was added rapidly using a multi-channel pipette and the plate was incubated at $37^{\circ} \mathrm{C}$ for $15 \mathrm{~min}$. Following incubation, $60 \mu \mathrm{L}$ of AAPH was added to each well and fluorescence was read using an excitation wavelength of $483 \mathrm{~nm}$ and an emission wavelength of $525 \mathrm{~nm}$ over 90 minutes at $37^{\circ} \mathrm{C}$ using a Tecan Safire ${ }^{2}$ plate reader (Tecan USA, Raleigh, NC). Samples and standards were measured in triplicate. Antioxidant capacity was expressed as $\mu \mathrm{mol}$ Trolox equivalents (TE) per gram of peanut skins.

\subsection{Cell Culture}

RAW 264.7 cells were cultured with Dulbecco's modified Eagle's medium (DMEM) containing 10\% FBS and $1 \%$ antibiotics $(40 \mathrm{U} / \mathrm{mL}$ penicillin and $40 \mu \mathrm{g} / \mathrm{mL}$ streptomycin), under $10 \% \mathrm{CO}_{2}$ at $37^{\circ} \mathrm{C}$. Cell viability was assessed using the 3-(4,5-dimethylthiazol-2-yl)-2,5-diphenyl tetrazolium bromide (MTT) assay [25].

To determine the cytotoxicity of PSE, cells were plated in 96-well plates $\left(3 \times 10^{5}\right.$ cells/well) using fresh media and measured using the MTT assay. Cellular metabolic activity is determined in this method by means of NAD(P)H-dependent cellular oxidoreductase enzymes which under standard conditions are proportional to the number of live cells [25]. Solutions of PSE were prepared by dissolving the freeze dried powders in ethanol $/$ water $(5 / 45 \mathrm{v} / \mathrm{v})$ at levels of $1 \%$ and $5 \%$. After overnight growth, cells were pretreated with the PSE solutions for $2 \mathrm{hr}$. To ensure the cells were not affected by solvent, testing was done on $10 \%$ ethanol in water solutions alone. Testing was also performed in the presence and absence of LPS at $1 \mu \mathrm{g} / \mathrm{mL}$. MTTsolution $(7.8 \mathrm{mg} / \mathrm{mL})$ in phosphate buffered saline (Sigma Chemical Corp., St. Louis, MO) was added to each well and the plates were incubated for $4 \mathrm{hr}$. The purple formazan crystals deposited were dissolved in $200 \mu \mathrm{L}$ of acidified isopropanol $(0.04 \mathrm{~N} \mathrm{HCl}$ in isopropanol). The absorbance of the resulting colored solution was measured at $620 \mathrm{~nm}$ using the previously described plate reader. The absorbance was compared to a negative control where no PSE was added to the cells reported as percentage of the control.

\subsection{Anti-Inflammatory Activity}

For the measurement of $\mathrm{PGE}_{2}$, a monoclonal enzyme linked immunosorbent assay (ELISA) kit (Cayman Chemical, Ann Arbor, MI) specific for this PG was used. RAW 264.7 cells were cultured in the presence or absence of LPS $(1 \mu \mathrm{g} / \mathrm{mL})$ and/or PSE for a total of $16 \mathrm{hr}$. 
PSE was dissolved into $10 \%$ ethanol in water and added to the cells at levels of $1 \%, 2.5 \%$ and $5 \%$. Levels of $\mathrm{PGE}_{2}$ in the cell media were measured using the $\mathrm{PGE}_{2}$ ELISA according to the manufacturer's instructions. Standards ranging from 7.8 to $1000 \mathrm{pg} / \mathrm{mL}$ were used. The level of detection for the assay was $50 \mathrm{pg} / \mathrm{mL}$.

\subsection{Western Blotting of COX-2}

RAW 267.4 cells were cultured in the presence or absence of LPS $(1 \mu \mathrm{g} / \mathrm{mL})$ and/or PSE for $12 \mathrm{hr}$, then washed, harvested, homogenized and stored at $-80^{\circ} \mathrm{C}$ until Western blotting was performed. Electrophoresis was accomplished using 12\% Tris-glycine gels with a Novex Minicell XCell SureLock apparatus. Protein bands were then transferred on to a PDVF membrane. All supplies (gels, PDVF membranes, buffer solutions, Coomassie staining kit, electrophoresis chamber and transfer apparatus) were obtained from Life Technologies (Grand Island, NY). The COX-2 (murine) primary antibody (Cayman Chemical Co., Ann Arbor, MI) was incubated at a 1:300 dilution using a $5 \%$ nonfat dry milk solution prepared in 1x TBS (Tris-Buffered Saline). Cox protein bands were visualized after incubation with a HRP-labeled secondary anti-mouse antibody (Cell Signaling, Danvers, MA). Intensities of the bands were measured using an Alpha-imager Digital Imaging System (Protein Simple, Santa Clara, CA).

\subsection{Nitric Oxide Assay}

Nitric oxide levels in the cells were determined using the Greiss assay with modifications [26,27]. In this study, RAW 264.7 cells were cultured, challenged with LPS and dosed with A-PSE and E-PSE as described in section 2.7 for $18 \mathrm{hr}$. Nitrite levels in the culture media were measured using a Greiss assay kit (Promega, Madison, WI) according to the manufacturer's instructions. In brief, $50 \mu \mathrm{L}$ of Greiss reagent (equal volumes of $1 \%$ sulfanilamide $(\mathrm{w} / \mathrm{v})$ in $5 \%$ phosphoric acid and $0.1 \%(\mathrm{w} / \mathrm{v}) \mathrm{N}-$ 1-naphthylethylenediamine-HCL) was added to $50 \mu \mathrm{L}$ of cell culture media. The mixture was incubated for $10 \mathrm{~min}$ at room temperature. The absorbance of the mixture was measured at $520 \mathrm{~nm}$ using a Tecan Safire ${ }^{2}$ plate reader. Fresh culture media was used as the blank. A standard curve was constructed over the range of 1.56 to $100 \mu \mathrm{M}$ using sodium nitrite in water.

\subsection{Statistical Analysis}

Data were analyzed using the Statistical Analysis System software (SAS, Cary, NC). For TPC, H-ORAC, procyanidins, and MTT analyses, an analysis of variance was conducted with Proc GLM using Duncan's multiple comparison test to detect differences among means $(\alpha=0.05)$. A multifactor analysis of variance based on Proc Mixed with Tukey's test was used for the $\mathrm{PGE}_{2}$ analysis.

\section{Results and Discussion}

\subsection{Procyanidin Content}

HPLC chromatograms of PSE extracted with either acetone/water $(50 / 50 \mathrm{v} / \mathrm{v})$ or ethanol water $(90 / 10 \mathrm{v} / \mathrm{v})$ are shown in Figure 1. Chromatograms are normalized based on equivalent extract volumes. Peanut skins contained low levels of monomeric flavan-3-ols (DP1) and higher levels of procyanidin oligomers and polymers. The profiles observed in this study are similar to those previously reported [22,28]. Previous studies have confirmed that the procyanidin oligomers in peanut skins contain both B-linkages as well as the less common A-type linkages [28-30]. Overall, the profiles produced by the two solvent systems were similar; however, it is visually evident that acetone/water was a more effective extraction solvent for procyandins than ethanol/water as indicated by the larger peak areas. Table 1 shows the concentration of the individual procyanidins extracted from the peanut skins. Each class of procyanidins, excluding DP1, was extracted at higher levels by acetone/water than by ethanol/water. There was no significant difference in extraction efficiency of DP1 procyanidins between the two solvent systems. These findings support previous literature reports that aqueous acetone is a more effective solvent for high molecular weight procyandins, but more polar solvents such as ethanol and methanol are equally or more effective for extraction of monomeric flavan-3ols [31-33].

\subsection{Total Phenolics and Antioxidant Activity}

Peanut skins have been reported to contain a variety of bioactive compounds with phenolic moieties, including catechins, A-type and B-type procyanidin dimers, trimers, and tetramers [22-35]. Extraction of these compounds has been studied with various extraction solvents. Using the Folin-Ciocalteu method, TPC of peanut skins extracted with pure ethanol has been reported as $118 \mathrm{mg} / \mathrm{g}$ [11]. Under optimized conditions, similar levels were found with an ethanol-water mixture [9]. Another study found 90 - $125 \mathrm{mg} / \mathrm{g}$ TPC after optimizing extraction conditions for ethanol water mixtures and the solvent to mass ratio for peanut skins [2]. In our study, acetone/ water $(50 / 50 \mathrm{v} / \mathrm{v})$ was compared to ethanol/water $(90 / 10$ $\mathrm{v} / \mathrm{v}$ ) for the extraction of TPC. The TPC is reported in Table 2 for the peanut skins extracted in both solvent systems used. No significant difference was found between the solvent systems although both extractions resulted in higher levels of TPC than the studies in the literature. The acetone system resulted in higher levels of phenolics being extracted. This was attributed to the interaction of the more polar solvent with the polyphenolic 


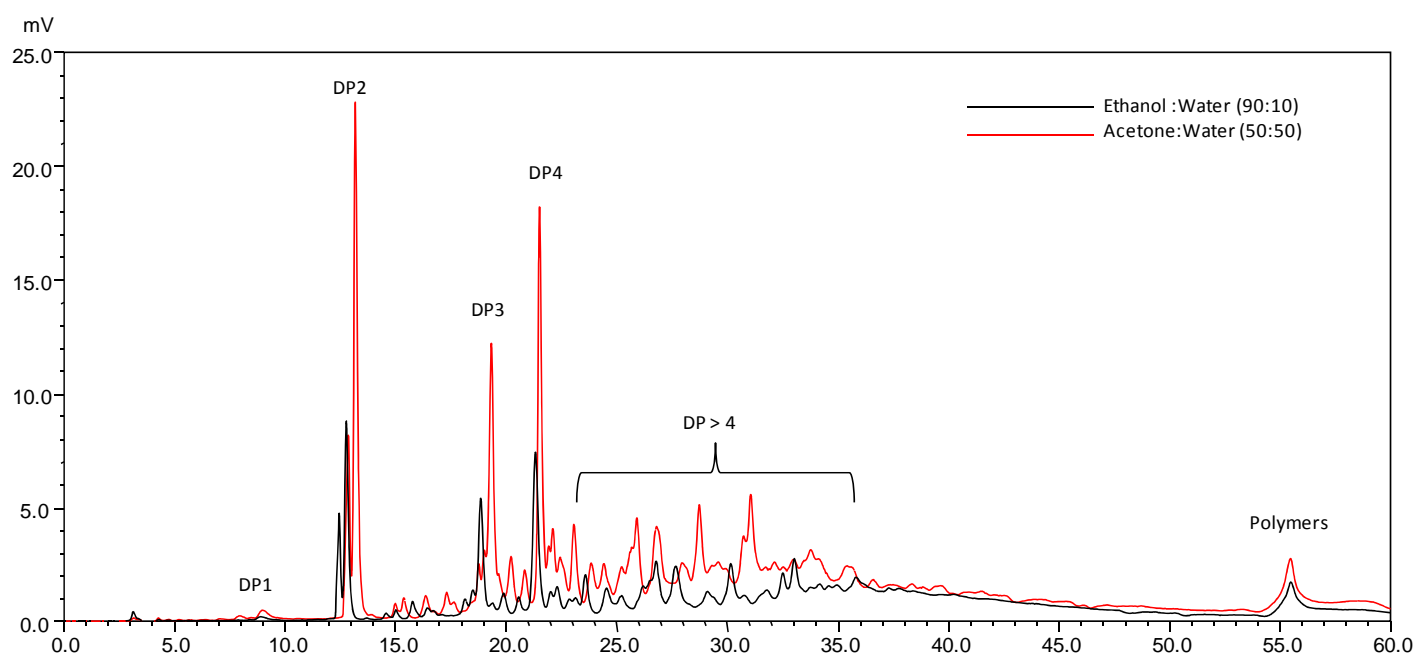

Figure 1. HPLC chromatogram of procyanidins in peanut skins extracted with acetone/water (red lines) or ethanol/water (black lines. Peaks identified based on previously published LC-MS analysis [22].

Table 1. Concentration of procyanidins in peanut skins (mg/g skins) extracted with different solvents.

\begin{tabular}{ccccccc}
\hline Solvent System & DP1 & DP2 & DP3 & DP4 & DP $>4$ & Polymers \\
\hline Acetone & $0.4 \pm 0.1$ & $7.9 \pm 1.0$ & $8.2 \pm 1.4$ & $12.9 \pm 2.0$ & $31.9 \pm 2.9$ & $5.2 \pm 0.8$ \\
Ethanol & $0.2 \pm 0.0$ & $4.0 \pm 0.6$ & $3.9 \pm 1.3$ & $7.9 \pm 1.8$ & $13.2 \pm 2.0$ & $2.7 \pm 0.7$ \\
p-value & 0.0668 & $0.0051^{*}$ & $0.0191^{*}$ & $0.0315^{*}$ & $0.0008^{*}$ & $0.0149^{*}$ \\
\hline
\end{tabular}

${ }^{*}$ Values in the same row significantly different based on $\mathrm{P}<0.005, \mathrm{n}=3$.

Table 2. Total phenolic content (TPC) and hydrophyllic oxygen radical absorbance capacity (H-ORAC) of peanut skins ${ }^{1}$.

\begin{tabular}{ccc}
\hline Solvent System & TPC $(\mathbf{m g ~ G A E} / \mathbf{g})$ & H-ORAC $(\boldsymbol{\mu m o l ~ T r o l o x} / \mathbf{g})$ \\
\hline Acetone & $67.9 \pm 1.8^{\mathrm{a}}$ & $1833 \pm 31^{\mathrm{a}}$ \\
Ethanol & $51.8 \pm 1.7^{\mathrm{a}}$ & $1830 \pm 58^{\mathrm{a}}$ \\
\hline
\end{tabular}

${ }^{1}$ Means within a column followed by the same letter were not significantly different $(\mathrm{p}<0.05, \mathrm{n}=3)$.

compounds present in the peanut skins. Although ethanol has been previously reported as a more effective solvent for the recovery of phenolic compounds, our work shows that acetone and ethanol resulted in similar effects. It is has been shown that acetone can be used to extract procyanidins, as well as other flavanol moieties [36]. It is possible that similar compounds maybe responsible for the higher phenolic activity associated with the acetone fractions in our study.

H-ORAC was used to measure the peroxyl radicalscavenging ability of PSE based on the Trolox antioxidant standard. Although the hydroxyl radical, singlet oxygen, superoxide radical and reactive nitrogen species are known to exist in biological systems, the peroxyl radical is most often present [37]. ORAC assays also provide a controllable source of peroxyl radicals that reflect the interaction of antioxidants with lipids in both food and physiological systems [38]. Our analysis showed that there was no significant difference between the values for the two solvent systems. This study found $1833 \mu \mathrm{mol} \mathrm{TE} / \mathrm{g}$ in the peanut skins extracted with acetone and $1830 \mu \mathrm{mol} \mathrm{TE} / \mathrm{g}$ in those extracted with ethanol as reported in Table 2.

Other reports list values of $2049 \mu \mathrm{mol} \mathrm{TE} / \mathrm{g}$ of peanut skins when a $30 \%$ ethanol in water solution was used and $2789 \mu \mathrm{mol} \mathrm{TE} / \mathrm{g}$ when using $40 \%$ methanol in water [11]. Our conditions required longer times, but less heat and solvent than the literature. In comparison with other foods, peanut skins are well positioned to be considered a source of antioxidant compounds. For Chardonnay and Merlot grade seeds, values of 638 and $345 \mu \mathrm{mol} \mathrm{TE} / \mathrm{g}$ respectively have been reported [6]. There is a report of $92.1 \mu \mathrm{mol} \mathrm{TE} / \mathrm{g}$ for blueberries and $92.6 \mu \mathrm{mol} \mathrm{TE} / \mathrm{g}$ for cranberries, two foods that have been much discussed for their antioxidant properties [36]. Certain spices are also considered to be significant sources of antioxidant compounds based on their ORAC values. Of these, ground cinnamon is listed as the highest with $2641 \mu \mathrm{mol} \mathrm{TE} / \mathrm{g}$ [37]. The high antioxidant values observed for the peanut skins rank them with the spices in terms of ORAC. The physical nature of the dried peanut skin extracts suggests food applications similar to those for ground spices ra- 
ther than intact fruits.

\subsection{Cytotoxicity}

In order to study the potential anti-inflammatory effects of PSE, it was first necessary to determine non-toxic doses of the extracts. The MTT assay was used to determine the maximum amounts of PSE that could be added to the cells before cell viability was affected. In Figure 2, the effect of the addition of PSE on cell viability from both solvent systems at two levels is presented. All treatments resulted in small decreases in cell viability compared with the negative control, but none of the decreases were significant. PSE were reconstituted in ethanol $(10 \%$ in water $(\mathrm{v} / \mathrm{v}))$ from the dried powders, then added to the cell culture media in order to examine cytotoxicity. The two solvent systems produced different amounts of dried powders as reported in Table 3. On a dry weight basis, the acetone solution extracted almost twice as much solid material as the ethanol solution. The actual TPC and H-ORAC of these highly concentrated extract powders was much higher than those calculated for the peanut skins on an as received basis (Table 2). Ethanol extracted peanut skins (E-PSE) had slightly greater effects on cell viability than the acetone extracted peanut skins (A-PSE). This may have been related to

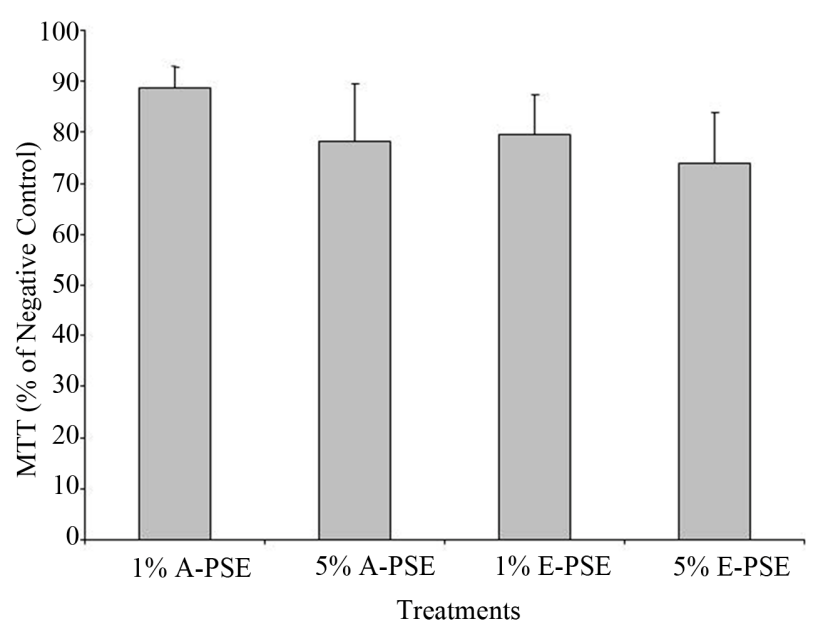

Figure 2. Viability of RAW 264.7 cells treated with $1 \%$ or $5 \%$ PSE for $12 \mathrm{hr}$ relative to a negative control $(\mathrm{n}=3)$.

Table 3. Total solids (TS), total phenolic content (TPC), hydrophillic oxygen radical absorbance capacity (H-ORAC), total proanthocyanidin content (TPAC) of peanut skin extract (PSE) powders.

\begin{tabular}{ccccc}
\hline Solvent & TS $^{1}$ & TPC $^{2}$ & H-ORAC $^{3}$ & TPAC $^{4}$ \\
\hline Acetone & 16.1 & 431.3 & 203,297 & 368.7 \\
Ethanol & 9.7 & 377.1 & 305,598 & 266.3 \\
\hline
\end{tabular}

${ }^{1}$ gPSE/g Peanut Skins; ${ }^{2} \mathrm{mg} \mathrm{GAE} / \mathrm{g}$ PSE; ${ }^{3} \mu \mathrm{Mol}$ TE/g PSE; ${ }^{4} \mathrm{mg} / \mathrm{g}$ PSE. All values are means of 3 measurements. differences between the two solvent systems, as evidenced by differences in procyanidin and TPC of the extracts since differences in solvent polarity affected the compounds extracted. It was also found that the small amount of ethanol $(10 \%$ solution) used to solubulize the PSE powders had no effect on cell viability (data not shown).

\subsection{Anti-Inflammatory Activity}

$\mathrm{PGE}_{2}$ is a major product of arachidonic acid metabolism in many cells, including macrophages [39]. It is not stored, but is synthesized and expressed into extracellular media when cells are activated by pro-inflammatory stimuli [14]. The addition of the pro-inflammatory mediator LPS to RAW 264.7 cells growth media resulted in increased $\mathrm{PGE}_{2}$ formation as seen in the positive control in Figure 3. By comparison, the negative control shows significantly lower levels of $\mathrm{PGE}_{2}$ formation. Cells cotreated with LPS and A-PSE show significant decreases in $\mathrm{PGE}_{2}$ only at the highest level, while cells co-treated with LPS and E-PSE showed significant decreases in $\mathrm{PGE}_{2}$ both at the $2.5 \%$ and $5 \%$ levels. Decreased expression of COX-2 was considered to be at least partly responsible for the observed inhibition of $\mathrm{PGE}_{2}$ production, since the COX-2 enzyme converts arachidonic acid to $\mathrm{PGH}_{2}$, the direct precursor of $\mathrm{PGE}_{2}$.

Activation of macrophages is needed for the progresssion of many inflammatory diseases due to the release of such mediators such as cytokines, nitric oxide and prostaglandins [40]. The observed suppression of $\mathrm{PGE}_{2}$ formation in this study maybe a consequence of the high levels of procyandins present in the extracts. A study using acid hydrolyzed aqueous extracts from peanut skins reported inhibition of $\mathrm{PGE}_{2}$ activity [41]. The authors attributed this activity to the presence of cyandin 3-sambubioside, which is an anthocyanidin originating in peanut skins.

\subsection{COX-2 Protein Expression}

The inhibition of COX-2 protein expressed by the RAW 264.7 cells as a consequence of the exposure to the PSE solutions after stimulation by LPS was determined by Western Blot analysis. No COX-2 protein expression was detected in the un-stimulated cells. When challenged with LPS to induce an inflammatory response, the COX-2 expression levels were elevated. PSE from both extraction systems suppressed COX-2 expression in a dose-dependent manner as seen in Figure 4. PSE was not found to affect the expression of the housekeeping gene, $\beta$-actin. Given their high concentration in PSE, it is feasible that the polyphenols present in the extract inhibited the expression of the COX-2 protein. These compounds, which include flavonoids, have been studied for their anti-inflammatory activity both in vivo and in vitro in 


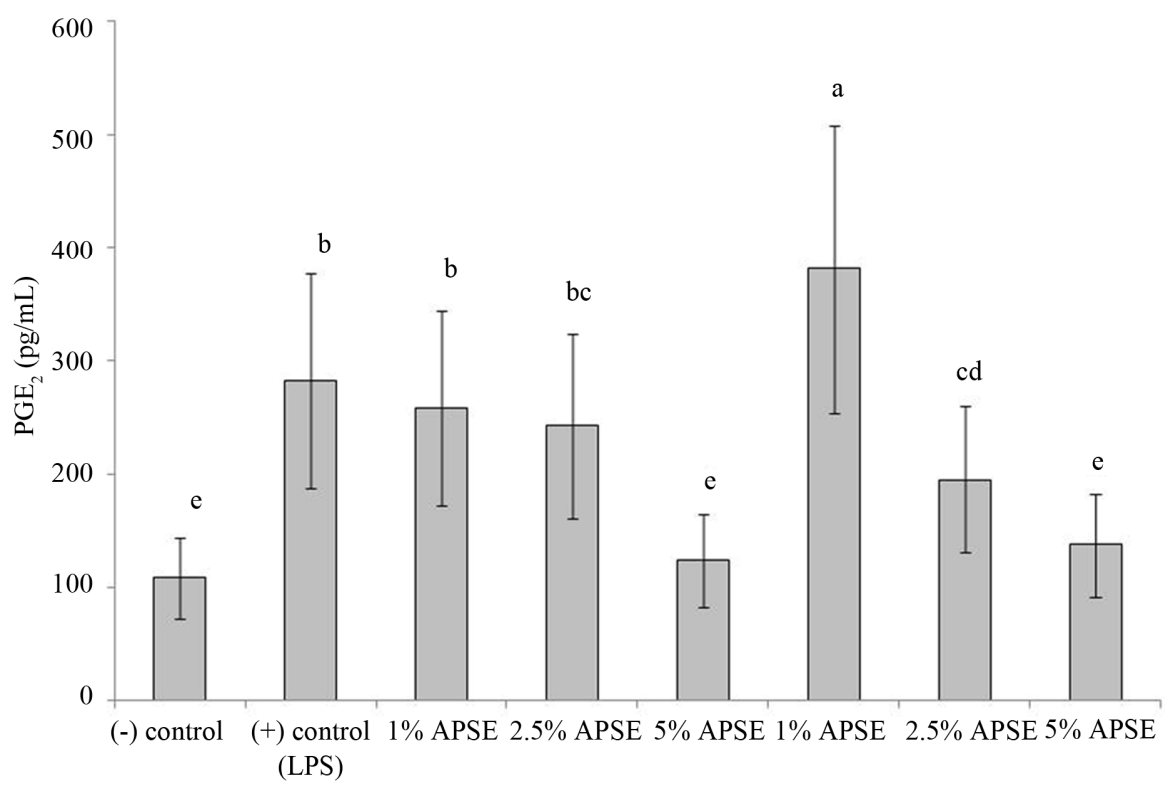

Figure 3. Concentration effect of the PSE on PGE 2 content of RAW 264.7 cells after challenge with LPS. Bars with different letters were significantly different $(P<0.05) ; n=3$.
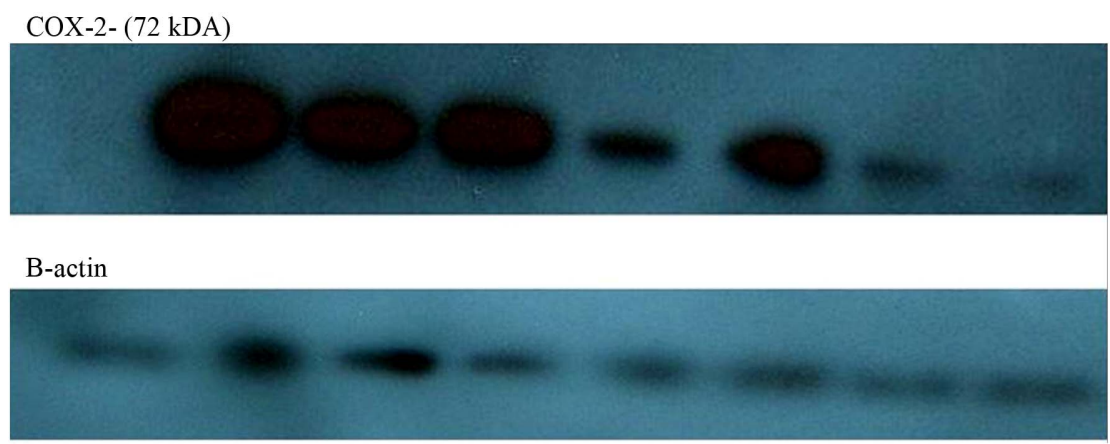

-control +control $1 \%$ E-PSE $2.5 \%$ E-PSE $5 \%$ E-PSE $1 \%$ A-PSE $2.5 \%$ A-PSE $5 \%$ A-PSE

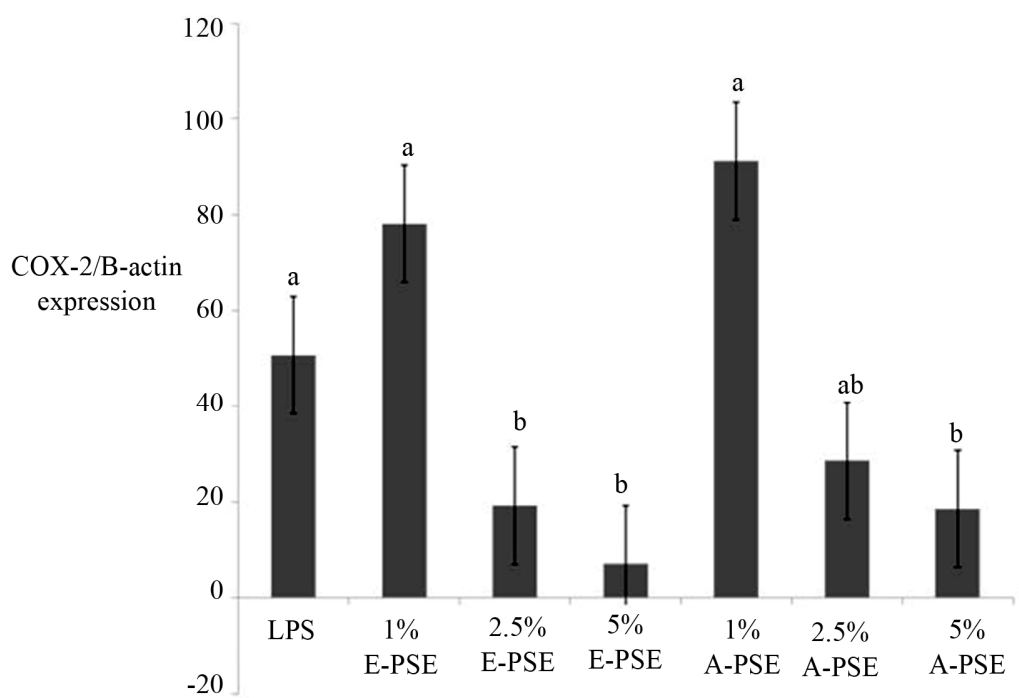

Figure 4. The COX-2 band intensities have been compared to the $\beta$-actin bands in the corresponding gel rows. Bars with different letters were significantly different $(P<0.05) ; n=3$. 
other fruits and vegetables [42-44]. It has been observed that the structures of these compounds are important to their anti-inflammatory activity [45]. Flavonoids such as epigallocatechin gallate appear to inhibit COX-2 and $\mathrm{PGE}_{2}$ induction due to the presence of the $\mathrm{C}-2,3$ double bond and the hydroxyl or methoxyl moieties on the $\mathrm{A}$ and $\mathrm{B}$ rings [46]. These types of compounds have been reported in peanut skins [5]. The dose-dependent inhibition of these pro-inflammatory markers demonstrates the anti-inflammatory properties of PSE but the definite cellular mechanisms still need to be established.

\subsection{Nitric Oxide (NO) Production}

In an attempt to further understand how peanut skin extracts may modulate inflammation, the effects of PSE on NO production in the LPS-stimulated cells was also examined. NO plays a variety of important roles throughout the body, among them, vasodilation, immunity and neurotransmission, as well as inflammation [47]. Both APSE and E-PSE inhibited NO production from the LPSactivated RAW-264.7 cells in a dose dependent manner as seen in Figure 5. There is the possibility that low levels of PSE are proinflammatory, as the production of NO was increased when $1 \%$ PSE was present in the media as indicated by the increase in NO in the non-LPS stimulated control cells over the basal value. The expression of iNOS is controlled by a different pathway than $\mathrm{PGE}_{2}$. It is the activation of NF- $\kappa \mathrm{B}$, a transcription factor that causes this inflammatory response [48]. It would be of interest to further this research by investigating the effects of PSE on NF- $\kappa \mathrm{B}$ production. It has been reported that NF $-\kappa B$ is inhibited by peanut stilbenoids [49]. Other compounds that are known to exists in peanut skins such as phenolic acids and catechins have been shown to have

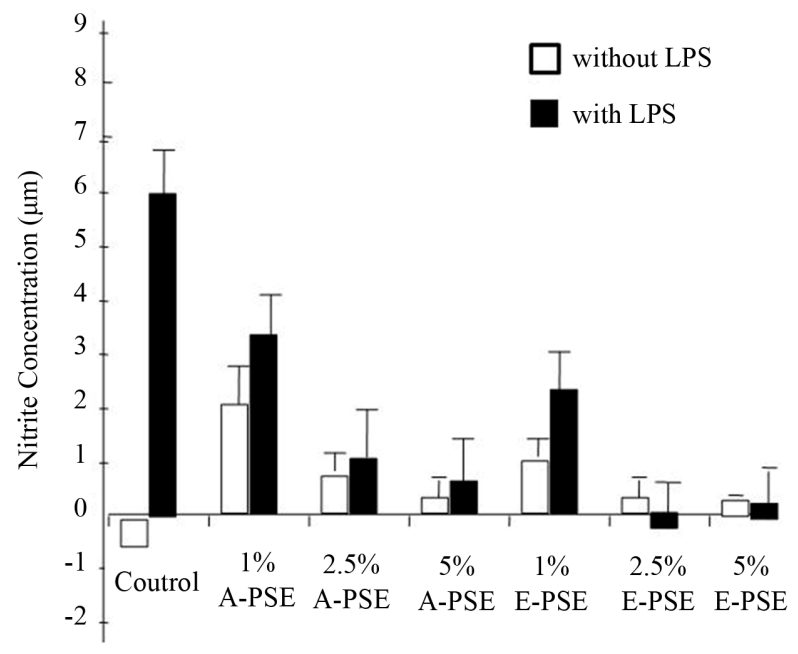

Figure 5. Concentration effects of the PSE on NO production by RAW 264.7 cells with and without LPS challenge (n =3). inhibitory effects on iNOS and NF- $\kappa \mathrm{B}$ expression [5054]. In those cases, the active compound inhibited activation of the iNOS promoter by preventing the binding of the essential transcription factor $(\mathrm{NF}-\kappa \mathrm{B})$ to the iNOS promoter.

\section{Conclusion}

This study showed that peanut skin extracts contain high levels of procyanidins and other phenolic compounds, whether extracted with acetone or ethanol. Despite measureable differences in procyanidin and phenolic content between the two extraction systems studied, both possessed similar antioxidant activity as determined by chemical assays and anti-inflammatory activity in an in vitro model of inflammation. The addition of PSE to LPS challenged macrophages resulted in decreased COX-2 expression, as well as in decreased $\mathrm{PGE}_{2}$ and $\mathrm{NO}$ levels, although the exact mechanism of the activity was not determined. Due to their low cost, peanut skins have great potential to serve as an economical source of natural antioxidants for the food and nutraceutical industries.

\section{Acknowledgements}

The authors wish to thank Ms. Kristin Price for technical assistance and Dr. Debra Clare for assistance with the manuscript preparation. Mention of a trademark or proprietary product does not constitute a guarantee or warranty of the product by the United States Department of Agriculture nor does it imply approval to the exclusion of other products that may be suitable.

\section{REFERENCES}

[1] T. H. Sanders, R. W. McMichael and K. W. Hendrix, "Occurrence of Resveratrol in Edible Peanuts," Journal of Agricultural and Food Chemistry, Vol. 48, No. 4, 2000, pp. 1243-1246. doi:10.1021/jf990737b

[2] J. Yu, M. Ahmedna and I. Goktepe, "Effects of Processing Methods and Extraction Solvents on Concentration and Antioxidant Activity of Peanut Skin Phenolics," Food Chemistry, Vol. 90, No. 1-2, 2005, pp. 199-206. doi:10.1080/10408390701640718

[3] B. W. Bolling, D. L. McKay and J. B. Blumberg, "The Phytochemical Composition and Antioxidant Actions of Tree Nuts," Asia Pacific Journal of Clinical Nutrition, Vol. 19, No. 1, 2010, pp. 117-123.

[4] P. J. Sarnoski, R. R. Boyer and S. F. O’Keefe, "Applications of Proanthocyanindins from Peanut Skins as a Natural Yeast Inhibitory Agent," Journal of Food Science, Vol. 77, No. 4, 2012, pp. M242-M249.

[5] M. L. D. L. Francisco and A. V. A. Resurreccion, "Functional Components of Peanuts," Critical Reviews in Food Science and Nutrition, Vol. 48, No. 8, 2008, pp. 715-746. doi:10.1080/10408390701640718

[6] Y. Yilmaz and R. T. Toledo, "Oxygen Radical Absor- 
bance Capacities of Grape/Wine Industry Byproducts and Effect of Solvent Type on Extraction of Grape Seed Polyphenols," Journal of Food Composition and Analysis, Vol. 19, No. 1, 2006, pp. 41-48. doi:10.1016/j.jfca.2004.10.009

[7] G. M. Hill, "Peanut By-Products Fed to Cattle," The Veterinary Clinics of North America, Food Animal Practices, Vol. 18, No. 2, 2002, pp. 295-315.

[8] V. Nepote, N. Grosso and C. Guzman, "Extraction of Antioxidant Components from Peanut Skins," Grasas y Aceites, Vol. 53, No. 4, 2002, pp. 391-395. doi:10.3989/gya.2002.v53.i4.335

[9] V. Nepote, N. Grosso and C. Guzman, "Optimization of Extraction of Antioxidants from Peanut Skins," Journal of the Science of Food and Agriculture, Vol. 85, No. 1, 2005, pp. 33-38. doi:10.1002/jsfa.1933

[10] H. Van Ha, J. Pokorny and H. Sakurai, "Peanut Skin Antioxidants," Journal of Food Lipids, Vol. 14, No. 3, 2007, pp. 298-314.

[11] T. Ballard, P. Mallikarjunan, K. Zhou and S. O'Keefe, "Optimizing the Extraction of Phenolic Antioxidants from Peanut Skins Using Response Surface Methodology," Journal of Agricultural and Food Chemistry, Vol. 57, No. 8, 2009, pp. 3064-3072. doi:10.1021/jf8030925

[12] P. Needleman, "Arachidonic Acid Metabolims," Annual Review of Biochemistry, Vol. 55, 1986, pp. 69-102. doi:10.1146/annurev.bi.55.070186.000441

[13] J. P. Portanova, Y. Zhang, G. D. Anderson, S. D. Hauser, J. L. Masferrer, K. Seibert, S. A. Gregory and P. C. Isakson, "Selective Neutralization of Prostaglandin E2 Blocks Inflammation, Hyperalgesia, and Interleukin 6 Production in Vivo," Journal of Experimental Medicine, Vol. 184, No. 3, 1996, pp. 883-891. doi:10.1084/jem.184.3.883

[14] M. Hamberg and B. Samuelsson, "On the Metabolism of Prostaglandins $\mathrm{E}_{1}$ and $\mathrm{E}_{2}$ in Man," Journal of Biological Chemistry, Vol. 246, No. 22, 1971, pp. 6713-6721. http://www.jbc.org/content/246/22/6713.full.pdf + html

[15] J. R. Vane, Y. S. Bakhle and R. M. Botting, "Cyclooxygenases 1 and 2," Annual Review of Pharmacology and Toxicology, Vol. 38, 1998, pp. 97-120. doi:10.1146/annurev.pharmtox.38.1.97

[16] C. J. Huang and M. C. Wu, "Differential Effects of Food Traditionally Regarded as 'Heating' and 'Cooling' on Prostaglandin $\mathrm{E}_{2}$ Production by a Macrophage Cell Line," Journal of Biomedical Science, Vol. 9, No. 6, 2002, pp. 595-606. doi:10.1007/BF02254987

[17] A. Escarpa and M. C. Gonzales, "An Overview of Analytical Chemistry of Phenolic Compounds in Foods," Critical Reviews in Analytical Chemistry, Vol. 31, No. 2, 2001, pp. 57-139. doi:10.1080/20014091076695

[18] B. Halliwell and M. Whitman, "Measuring Reactive Species and Oxidative Damage and in vivo and Cell Culture: How Should You Do It and What Do the Results Mean?" British Journal of Pharmacology, Vol. 246, No. 2, 2004, pp. 231-255.

[19] X. Han, T. Shen and H. Lou, "Dietary Polyphenols and Their Biological Significance," International Journal of Molecular Science, Vol. 8, No. 9, 2007, pp. 950-988. doi:10.3390/i8090950

[20] M. Bhaskaran, S. Shukla, J. K. Srivastava and S. Gupta, "Chamomile: An Anti-inflammatory Agent Inhibits Inducible Nitric Oxide Synthase Expression by Blocking RelA/ p65 Activity," International Journal of Molecular Medicine, Vol. 26, No. 6, 2010, pp. 935-940.

doi:10.3892/ijmm 00000545

[21] M. L. Hu, "Dietary Polyphenols as Antioxidants and Anticancer Agents: More Questions than Answers," Chang Guang Medical Journal, Vol. 34, No. 5, 2011, pp. 449460. http://memo.cgu.edu.tw/cgmj/3405/340501.pdf

[22] K. E. Constanza, B. L. White, J. P. Davis, T. H. Sanders and L. L. Dean, "Value-Added Processing of Peanut Skins: Antioxidant Capacity, Total Phenolics, and Procyanidin Content of Spray-Dried Extracts," Journal of Agricultural and Food Chemistry, Vol. 60, No. 43, 2012, pp. 10776 10783. doi:10.1021/jf3035258

[23] V. L. Singleton and J. A. Rossi, "Colorimetry of Total Phenolics with Phosphomolybdic-phosphotungstic Acid Reagents," American Journal of Enology and Viticulture, Vol. 16, No. 3, 1965, pp. 144-158.

http://www.ajevonline.org/content/16/3/144.full.pdf + html

[24] R. L. Prior, H. Hoang, L. Gu, X. Wu, M. Bacchiocca, L. Howard, M. Hampsch-Woodill, D. Huang, B. Ou and R. Jacob, "Assay for Hydrophilic and Lipophilic Antioxidant Capacity (Oxygen Radical Absorbance Capacity (ORACFL)) of Plasma and Other Biological and Food Samples," Journal of Agricultural and Food Chemistry, Vol. 51, No. 11, 2003, pp. 3273-3279. doi:10.1021/jf0262256

[25] T. Mosmann, "Rapid Colorimetric Assay for Cellular Growth and Survival: Application to Proliferation and Cytotoxicity Assays." Journal of Immunological Methods, Vol. 65, No. 1-2, 1983, pp. 55-63. doi:10.1016/0022-1759(83)90303-4

[26] A. Campos-Neto, P. Ovendale, T. Bement, T. A. Koppi, W. C. Fanslow, M. A. Rossi and M. R. Alderson, "CD40 Ligand is not Essential of the Development of Cell Mediated Immunity and Resistance to Mycobacterium tuberculosis," Journal of Immunology, Vol. 160, No. 5, 1998, pp. 2037-2041.

http://www.jimmunol.org/content/160/5/2037.full

[27] S. Y. Chaea, M. Lee, S. W. Kim and Y. H. Bae, "Protection of Insulin Secreting Cells from Nitric Oxide Induced Cellular Damage by Crosslinked Hemoglobin," Biomaterials, Vol. 25, No. 5, 2004, pp. 843-850. doi:10.1016/S0142-9612(03)00605-7

[28] S. A. Lazarus, G. E. Adamson, J. F. Hammerstone and H. H. Schmitz, "High-Performance Liquid Chromatography/ Mass Spectrometry Analysis of Proanthocyanidins in Food and Beverages," Journal of Agricultural and Food Chemistry, Vol. 47, No. 9, 1999, pp. 3693-3701. doi:10.1021/jf9813642

[29] M. Monagas, I. Garrido, R. Lebron-Aguilar, M. C. GomezCordoves, A. Rybarczyk, R. Amarowicz and B. Bartolome, "Comparative Flavan-3-ol Profile and Antioxidant Capacity of Roasted Peanut, Hazelnut, and Almond Skins," Journal of Agricultural and Food Chemistry, Vol. 57, No. 22, 2009, pp. 10590-10599. doi:10.1021/jf901391a

[30] P. J. Sarnoiski, J. V. Johnson, K. A. Reed, J. M. Tanko and 
S. F. O'Keefe, "Separation and Characterization of Proanthocyanidins in Virginia Type Peanut Skins by LCMS $^{\mathrm{n}}$," Food Chemistry, Vol. 131, No. 3, 2012, pp. 927939. doi:10.1016/j.foodchem.2011.09.081

[31] G. K. Jayaprakasha, T. Selvi and K. K. Sakariah, "Antibacterial and Antioxidant Activities of Grape (Vitis vinifera) Seed Extracts," Food Research International, Vol. 36, No. 2, 2003, pp. 117-122.

[32] S. Kallithraka, C. Garcia-Viguera, P. Bridle and J. Bakker, "Survery of Solvents for the Extraction of Grape Seed Phenolics," Phytochemical Analysis, Vol. 6, No. 5, 1995, pp. 265-267. doi:10.1002/pca.2800060509

[33] J. F. Hammerstone, S. A. Lazarus, A. E. Mitchell, R. Rucker and H. H. Schmitz, "Identification of Procyanidins in Cocoa (Theobroma cacao) and Chocolate Using HighPerformance Liquid Chromatography/Mass Spectrometry," Journal of Agricultural and Food Chemistry, Vol. 47, No. 2, 1999, pp. 490-496. doi:10.1021/jf980760h

[34] J. Yu, M. Ahmedna, I. Goktepe and J. Dai, "Peanut Skin Procyanidins: Composition and Antioxidant Activities as Affected by Processing," Journal of Food Composition and Analysis, Vol. 19, No. 4, 2006, pp. 364-371. doi:10.1016/j.jfca.2005.08.003

[35] J. J. Karchesy and W. W. Hemingway, "Condensed Tannins: $(4 \beta \rightarrow 8 ; 2 \beta \rightarrow \mathrm{O} \rightarrow 7$ )-Linked Procyanidins in Arachis hypogaea L," Journal of Agricultural and Food Chemistry, Vol. 34, No. 6, 1986, pp. 966-970. doi:10.1021/if00072a009

[36] H. Lou, Y. Ymazaki, T. Sasaki, M. Uchida, H. Tanaka and S. Oka, "A-Type Proanthocyanidins from Peanut Skins," Phytochemistry, Vol. 51, No. 2, 1999, pp. 297-308.

[37] X. Wu, G. R. Beecher, J. M. Holden, D. B. Haytowitz, S. E. Gebhardt and R. L. Prior, "Lipophilic and Hyrophilic Antioxidant Capacities of Common Foods in the United States," Journal of Agricultural and Food Chemistry, Vol. 42, No. 12, 2004, pp. 4026-4037. doi:10.1021/jf049696w

[38] R. L. Prior, X. Wu and K. Schaich, "Standardized Methods for the Determination of Antioxidant Capacity and Phenolics in Foods and Dietary Supplements," Journal of Agricultural and Food Chemistry, Vol. 53, No. 10, 2005, pp. 4290-4302. doi:10.1021/jf0502698

[39] E. Granström, M. Hamberg, G. Hansson and H. Kindahl, "Chemical Instability of 15-Keto-13,14-dihydro-PGE 2 : The Reason for Low Assay Reliability," Prostaglandins, Vol. 19, No. 6, 1980, pp. 933-945.

[40] Y. Liang, Y. Huang, S. Tsai, S. Lin-Shiau, C. Chen and L. Lin, "Supression of Inducible Cyclooxygenase and Inducible Nitric Oxide Synthase by Apigenin and Related Flavonoids in Mouse Macrophages," Carcinogenisis, Vol. 20, No. 10, 1999, pp. 1945-1952. http://carcin.oxfordjournals.org/content/20/10/1945.full.p df

[41] J.-C. Cheng, L.-S Kan, J.-T. Chen, L.-G. Chen, H.-C. Lu, S.-M. Lin, S.-H. Wang, K.-H. Yang and R. Y.-Y. Chiou, "Detection of Cyanidin in Different-colored Peanut Testae and Identification of Peanut Cyanidin 3-Sambubioside," Journal of Agricultural and Food Chemistry, Vol. 57, No. 19, 2009, pp. 8805-8811. doi:10.1021/jf902512k
[42] Y. S. Chi, B. S. Cheon and H. P. Kim, "Effect of Wogonin, a Plant Flavone from Scutellaria radix, on the Suppression of Cyclooygenase and the Induction of Inducible Nitric Oxide Synthase in Lipopolysaccharide-Treated RAW 264.7 Cells," Biochemical Pharmacology, Vol. 61, No. 10, 2001, pp. 1195-1203.

[43] A. Murakami, Y. Nakamura, T. Torikai, T. Koshiba, K. Koshimizu, S. Kuwahara, T. Yasuo, K. Ogawa, M. Yano, H. Tokuda, H. Nishino, Y. Mimaki, Y. Sahida, S. Kitanaka and H. Ohigashi, "Inhibitory Effect of Citrus Nobiletin on Phormol Ester-Induced Skin Inflammation, Oxidative Stress, and Tumor Promotion in Mice," Cancer Research, Vol. 60, No. 18, 2000, pp. 5059-5066. http://cancerres.aacrjournals.org/content/60/18/5059

[44] K. F. A. Soliman and E. A. Mazzio, "In Vitro Attenuation of Nitric Oxide Production in C6 Astrocyte Cell Culture by Various Dietary Compounds," Proceedings of the Society for Experimental Biology and Medicine, Vol. 218, No. 4, 1998, pp. 390-397.

[45] R. J. Williams, J. P. E. Spencer and C. A. Rice-Evans, "Flavonoids: Antioxidants of Signaling Molecules?" Free Radical Biology \& Medicine, Vol. 36, No. 7, 2004, pp. 838-849. doi:10.1016/j.freeradbiomed.2004.01.001

[46] H. P. Kim, K. H. Son, H. Chang and S. S. Kang, "Antiinflammatory Plant Flavonoids and Cellular Action Mechanisms," Journal of Pharmacological Sciences, Vol. 96, No. 3, 2004, pp. 229-245.

https://www.jstage.jst.go.jp/article/jphs/96/3/96_3_229/_ pdf

[47] H. H. Harald, W. Schmidt and U. Walter, "NO at Work," Cell, Vol. 78, No. 6, 1994, pp. 919-925.

[48] F. Aktan, "iNOS-mediated Nitric Oxide Production and Its Regulation," Life Sciences, Vol. 75, No. 6, 2004, pp. 639-653. doi:10.1016/j.lfs.2003.10.042

[49] V. Sobolev, S. I. Khan, N. Tabanca, D. E. Wedge, S. P. Manly, S. J. Cutler, M. R. Coy, J. J. Becnel, S. A. Neff and J. B. Gloer, "Biological Activity of Peanuts (Arachis hypogaea) Phytoalexins and Selected Natural and Synthetic Stilbenoids," Journal of Agricultural and Food Chemistry, Vol. 59, No. 5, 2011, pp. 1673-1682. doi:10.1021/jf104742n

[50] H. Y. Ahn, Y. Xu and S. T. Davidge, "Epigallocatechin3-O-gallate Inhibits TNFR-induced Monocyte Chemotactic Protein-1 Production from Vascular Endothelial Cells," Life Sciences, Vol. 82, No. 17-18, 2008, pp. 964-968. doi:10.1016/j.lfs.2008.02.018

[51] J. K. Kundu and Y. J. Surh, "Epigallocatechin Gallate Inhibits Phorbol Ester-Induced Activation of NF- $\kappa \mathrm{B}$ and CREB in Mouse Skin: Role of p38 MAPK," Annals of the New York Academy of Sciences, Vol. 1095, 2007, pp. 504-512. doi:10.1196/annals.1397.054

[52] K. W. Lee, J. K. Kundu, S. O. Kim, K. S. Chun, H. J. Lee and Y. J. Surh, "Cocoa Polyphenolds Inhibit Phorbol Ester-induced Superoxide Anion Formation in Cultured HL-60 Cells and Expression of Cyclooxygenase-2 and Activation of NF- $\mathrm{kB}$ and MAPKs in Mouse Skin in Vivo," Journal of Nutrition, Vo. 136, No. 5, 2006, pp. $1150-1155$. http://jn.nutrition.org/content/136/5/1150.full.pdf + html 
[53] M. H. Pan, C. S. Lai, S. Dushenkov and C. T. Ho, "Modulation of Inflammatory Genes by Natural Dietary Bioactive Compounds," Journal of Agricultural and Food Chemistry, Vol. 57, No. 11, 2007, pp. 4467-4477. doi:10.1021/jf900612n

[54] D. S. Wheeler, J. D. Catravas, K. Odoms, A. Denenberg,
V. Malhotra and H. R. Wong, "Epigallocatechin-3-gallate, a Green Tea-Derived Polyphenol, Inhibits IL-1 $\beta$-Dependent Proinflammatory Signal Transduction in Cultured Respiratory Epithelial Cells," Journal of Nutrition, Vol. 134, No. 5, 2004, pp. 1039-1044.

http://jn.nutrition.org/content/134/5/1039.full.pdf + html 